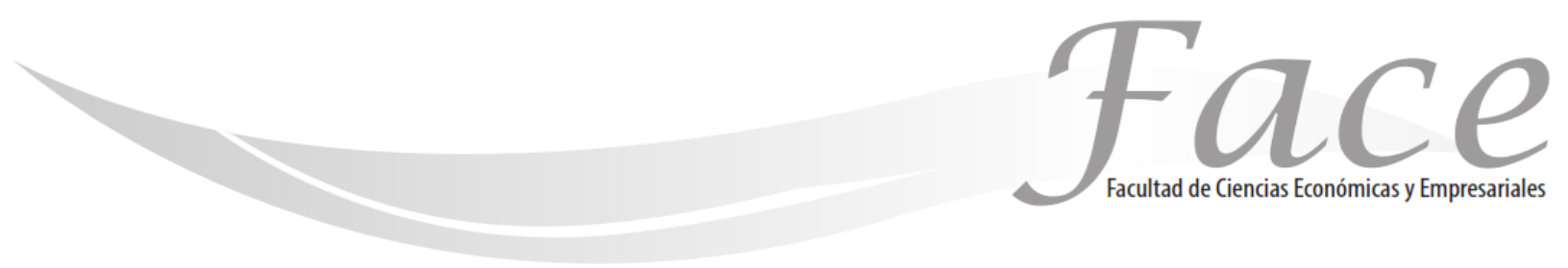

ISSN Impreso: 1794-9920

ISSN Electrónico: 2500-9338

Volumen 17-N¹

Año 2017

Págs. 44 - 54

\title{
CAUSAS E IMPACTO SOCIO-ECONÓMICO POR LIQUIDACIÓN DE LAS EMPRESAS COMERCIALES Y DE SERVICIOS*
}

\author{
Olga Lucia Galvis Pinzón ** \\ Enlace ORCID: http://orcid.org/0000-0001-6191-6010
}

Fecha de Recepción: Noviembre 26 de 2016

Fecha de Aprobación: Febrero 7 de 2017

\section{Resumen:}

La investigación abordó el análisis de las principales causas que generan la liquidación de las microempresas comerciales y de servicios en la ciudad de Barrancabermeja durante el período 2009-2013. El enfoque de la investigación parte del análisis de la gestión del riesgo como elemento transversal que permita identificar los criterios con los cuales se toman decisiones empresariales, así mismo se identificaron los indicadores económicos y las afectaciones socio-económicas por el cierre de las empresas, partiendo de fuentes primarias y secundarias con la base del estado del arte a nivel nacional y por último proponer una ruta de gestión estratégica del riesgo empresarial a través de una matriz que le permita al emprendedor contar con herramientas cualificadas que redunden en una mejor identificación y control del riesgo.

Palabras Claves: Comercio - Liquidación - Microempresas - Riesgo empresarial- Servicios.

\footnotetext{
* ORIGEN DEL ARTICULO: Producto de una investigación. Título: GESTIÓN DEL RIESGO FRENTE A LAS CAUSALES DE LIQUIDACIÓN EN LAS EMPRESAS COMERCIALES Y DE SERVICIOS DE LA CIUDAD DE BARRANCABERMEJA DURANTE EL PERIODO 2009-2013. Institución ejecutora: CONADI - UCC. Fase del proyecto: Terminado. Fecha inicio: 1/Junio/2015 y finalización: 1 Junio/2016.

** Docente Universidad Cooperativa de Colombia - Sede Barrancabermeja. Magister en Administración de Empresas. Correo electrónico: olga.galvis@campusucc.edu.co
} 


\title{
CAUSES AND SOCIO-ECONOMIC IMPACT ON THE LIQUIDATION OF COMMERCIAL AND SERVICE COMPANIES
}

\begin{abstract}
This research dealt the analysis about main causes which generate the liquidation of trade and services micro-enterprises in Barrancabermeja city from 2009 to 2013 period. The research focus starts with the management risk analysis as a transversal element that allows judgments to be identified and to make business decisions with. On the other hand, economic indicators were identified and socio-economic affectations due to the close of enterprises, through basic and secondary sources taking as a basis the State of Art nationwide. Finally, proposing a management strategic route about the business threat over a mold that affords to the entrepreneur counts on qualified tools result in a highest identification and control of risks.
\end{abstract}

Keywords: Trade - Liquidation - Micro-enterprises - Management risk - Services.

\section{CAUSAS E IMPACTO SÓCIO-ECONÓMICO PARA A LIQUIDAÇÃO DE COMÉRCIO E SERVIÇOS EMPRESAS}

\author{
Resumo
}

\begin{abstract}
A pesquisa abordou uma análise das principais causas que geram a liquidação das microempresas comerciais e de serviços na cidade de Barrancabermeja durante o período 2009-2013. O enfoque da pesquisa parte da análise da gestão do risco como elemento transversal que permita identificar os critérios sobre os quais se faz a tomada de decisões empresariais. Na segunda se identificaram os indicadores econômicos e as afetações socioeconômicas pelo fechamento das empresas, através de fontes primárias e secundarias com base no estado da arte a nível nacional; e por último, propor uma rota de gestão estratégica do risco empresarial por meio de uma matriz que permita ao empreendedor ter ferramentas qualificadas que redundem em uma melhor identificação e controle do risco.
\end{abstract}

Palavras-chave: Comércio - Liquidação - Microempresas - Risco empresarial- Serviço. 


\section{INTRODUCCIÓN:}

En economías de enclave ${ }^{1}$ la dinámica empresarial tiende a estar en función de la actividad del sector que jalona la economía, o de economías de aglomeración que producen estos modelos económicos. Esta circunstancia, aunada a factores legales, explica entre otras razones, buena parte de la actividad liquidataria de las empresas en un territorio. Las consecuencias que generan los procesos de mortalidad empresarial sobre el desarrollo económico de una comunidad son de alto impacto social, de manera especial en la destrucción del empleo, máxime cuando la tasa de desempleo de Barrancabermeja es superior a la nacional, 19, 9\% (CER 2013) para el 2013. Como característica especial, la ciudad de Barrancabermeja presenta en su estructura demográfica el fenómeno de Bono Demográfico ${ }^{2}$ el cual representa un contexto favorable, dado la representatividad de las personas en edades potencialmente productivas.

Los estudios a nivel nacional y de algunas ciudades de Colombia realizados por la Superintendencia de Sociedades, o los desarrollados por las Cámaras de Comercio, dan cuenta de algunas de las razones generales que generan la suspensión de actividades empresariales.

Ante la ausencia de estos esfuerzos investigativos en la ciudad, la presente investigación pretende abordar el análisis de las principales causas que generan la liquidación de las microempresas comerciales y de servicios en Barrancabermeja durante el período 20092013.

\section{MARCO TEÓRICO:}

La investigación centro su atención en teóricos como Sánchez (2005), Soriano (2005), Romero (2013) y Porter (citado por Mutis 2013) entre otros donde se tocan temas de fracaso empresarial para comprender la situación de las empresas en los ambientes de liquidación.

En el caso del análisis del fracaso empresarial, los estudios consisten en predecir si una empresa quebrará o se

\footnotetext{
${ }^{1}$ Se denomina economía de enclave a un modelo económico donde, en un mercado globalizado, se localizan actividades productivas en países subdesarrollados destinadas a la exportación y sin integrarse en el mercado local.

2 El Consejo Nacional de Población (CONAPO) define al bono demográfico como el fenómeno que se da dentro del proceso de transición demográfica en el que la población en edad de trabajar (económicamente activa) es mayor que la dependiente (niños y adultos mayores), y por tanto, el potencial productivo de la economía es superior.
}

mantendrá sana, a partir de información contenida en sus datos financieros. Así mismo, tratar de establecer qué variables o factores financieros están más estrechamente relacionadas, logrando explicar las razones del fracaso empresarial (Sánchez, 2005).

Las situaciones de fracaso empresarial (también conocidas como Insolvencia empresarial Deakin (citado por Romero 2013), quiebra Altman (citado por Romero 2013), estrés 0 fragilidad empresarial Martínez (citado por Romero 2013), han sido discutidas ampliamente en el contexto internacional y recientemente en Colombia. Por tanto, hay gran proliferación de investigaciones relacionadas con el tema y basadas en la construcción y aplicación de modelos estadísticos de capacidad predictiva. La mayoría de trabajos no se basan en una teoría económica del fracaso empresarial, ya que aún no hay un consenso y en consecuencia, no se cuenta con una metodología única y son generalmente insuficientes para concluir sobre una cuestión específica (Mateos et al., 2011); sin embargo, las diferentes opiniones y aportes empíricos han enriquecido el tema.

Según datos otorgados por Soriano (2005), las cifras de fracaso de las MYPES son alarmantes en cualquier país que se analicen. Las estadísticas indican que, en promedio, el $80 \%$ de ellas fracasa antes de los cinco años; mientras que el $90 \%$ no llega a 10 años. Por su parte, los empresarios sugieren que las causas de liquidación 0 cierre de las empresas, son netamente externas. No obstante, algunos analistas consideran que las razones se originan en el interior de estas compañías, especialmente en la gestión de sus responsabilidades.

Basado en algunos estudios realizados, a saber, el Modelo de William Beaver dado por Beaver (1966), Modelos Z de Altman explicada por Altman (1968) y Modelos Logit y Probit, impartido por Ohlson (1980), se determina que se debe no solo analizar la probabilidad de que se liquiden las empresas, sino estudiar las consecuencias futuras antes de que sucedan y con base a esto prevenir para que no siga presentándose el mismo número de efectos que perjudican la calidad de vida de la ciudadanía.

De acuerdo a Porter (2011), en su teoría de valor compartido, existe una estrecha relación entre las estrategias empresariales y algunos indicadores sociales: la pobreza, el entorno ambiental y la salud. La empresa siglo XXI no se considera aislada de la problemática social, sino por el contrario la fuente para la solución de las necesidades de las comunidades. Es de entender que su ausencia elimina oportunidades de crecimiento y desarrollo. Porter (citado por Mutis 2013) asegura que "las empresas deben redefinir sus estrategias para no solo generar riqueza a sus accionistas, sino también a la sociedad como un todo". De igual manera afirma que "las empresas que tengan como estrategia la creación de valor 
compartido son las que van a tener éxito en los próximos 20 años".

En la misma dirección, corroborando la relación empresa entorno, Paul A. Samuelson y William D. Nordhaus (Economía, 2005, p.537), economistas que han estudiado el crecimiento, comprobaron que el motor del progreso económico debe accionarse en cuatro ruedas, o factores de crecimiento como son: Recursos humanos (oferta de trabajo, educación, disciplina, motivación), recursos naturales (tierra, minerales, combustibles, calidad ambiental), formación de Capital (máquinas, fábricas, carreteras) y tecnología (ciencia, ingeniería, administración, empresariado).

Se observa que en estos factores de crecimiento económico se mencionan los aspectos del empleo, el empresariado, las fábricas, mezclando siempre el aspecto económico con el humano.

\section{METODOLOGÍA:}

La presente investigación tiene el enfoque cualitativo, "a veces referido como investigación naturalista, fenomenológica, interpretativa o etnográfica, es una especie de "paraguas" en el cual se incluye una variedad de concepciones, visiones, técnicas y estudios no cuantitativos" Grinnell (citado por Hernández 2006)

El instrumento utilizado en la presente investigación se realizó mediante una encuesta estructurada compuesta de 11 preguntas con opción de respuesta en cada una, el cual fue aplicado a los propietarios o personal con relación directa a las empresas encuestadas, inicialmente se valida el instrumento con 10 empresas localizadas recientes en el cierre como prueba piloto. La encuesta permitió identificar variables como las fortalezas y debilidades de las mismas, las fuentes de financiamiento, nivel de estudios y los diversos problemas que enfrentaron. Esta información fue relevante para realizar una descripción real del panorama y a su vez identificar las posibles causas de liquidación.

Los datos fueron obtenidos por medio de la Cámara de Comercio, los cuales antes de ser entregados fueron depurados para obtener un mejor resultado de los objetos a investigar. Se obtuvo una relación de 1211 empresas liquidadas junto con los datos básicos de los empresarios para así lograr contacto directo con los mismos.

$$
n \frac{(1.28)^{2} * 1211 * 0.5 * 0.5}{(1211-1) * 0.05^{2}+(1.28)^{2} * 0.5 * 0.5}=144
$$

El tamaño de la muestra fue de 144 empresas, de las cuales el $73,14 \%$ son de comercio y el $26,29 \%$ son de servicios. Con un coeficiente de confiabilidad del $90 \%$, el cual indica que de cada 100 empresas que existan en el mercado a 90 le aplica lo observado en esta investigación, aportando confiabilidad a los resultados.

Para el desarrollo del segundo objetivo específico se tuvo en cuenta el contexto nacional, considerando a la ciudad parte de ese todo, a fin de identificar los indicadores socioeconómicos que registran la realidad del país y en particular del Municipio, para lograr establecer dichas repercusiones. Se procedió a recolectar información de fuentes primarias y secundarias, para posterior revisión, identificación, selección, análisis crítico y descripción escrita de la información existente del tema.

Además del apoyo documental en textos en copia dura y digital e información registrada en internet, se recurre a consultas en documentos emitidos por entidades públicas entre ellas, la Cámara de Comercio de Barrancabermeja, el Departamento Administrativo Nacional de Estadística DANE, el Departamento Nacional de Planeación - DNP, entes relacionados con el tema: Comisión Económica para América Latina y el Caribe - CEPAL, y el Centro de Estudios Regionales del Magdalena Medio -CER.

En el proceso del desarrollo del tercer objetivo específico se toman fundamentalmente insumos de los resultados alcanzados en los anteriores objetivos para formular elementos de juicio que permitan al empresario anticiparse a los eventos de riesgo inherentes a la actividad empresarial de comercio y de servicios.

\section{RESULTADOS Y DISCUSIÓN:}

\section{CAUSALES DE LIQUIDACIÓN EN LAS EMPRESAS COMERCIALES Y DE SERVICIOS}

Tabla 1. ¿Cuáles considera usted fueron las principales causas de liquidación de la empresa? 


\begin{tabular}{|c|c|c|c|}
\hline & & Frecuencia & Porcentaje \\
\hline \multirow[t]{11}{*}{ Válido } & & 1 & .6 \\
\hline & Falta de experiencia & 19 & 10,9 \\
\hline & Mala Ubicación & 11 & 6,3 \\
\hline & $\begin{array}{l}\text { Mal manejo de } \\
\text { Inventarios }\end{array}$ & 24 & 13,7 \\
\hline & $\begin{array}{l}\text { Mala selección del } \\
\text { personal }\end{array}$ & 26 & 14,9 \\
\hline & $\begin{array}{l}\text { Sacar del negocio mucho } \\
\text { dinero para gastos } \\
\text { personales }\end{array}$ & 17 & 9,7 \\
\hline & Mala gestión del riesgo & 11 & 6,3 \\
\hline & Resistencia al cambio & 16 & 9,1 \\
\hline & $\begin{array}{l}\text { Graves errrores en } \\
\text { materia de seguridad }\end{array}$ & 6 & 3,4 \\
\hline & Otro & 44 & 25,1 \\
\hline & Total & 175 & 100,0 \\
\hline
\end{tabular}

La tabla demuestra que el $25,1 \%$ de los motivos pertenecen a las variables otro que contiene los casos de muerte, enfermedad, separación de socios, altos costos de arriendos, traslado de ciudad, la mala selección de personal que representa el 14,9\%; muchos empresarios expresaron su inconformidad por las pocas posibilidades que existen de dar confianza a los trabajadores puesto que estos los roban, no ejercen sus oficios, no cumplen con las responsabilidades 0 dañan la imagen de la empresa con sus comportamientos y actitudes hacia el cliente.

Grafica 1. ¿Cuál fue la reacción suya ante la decisión del cierre de la empresa?

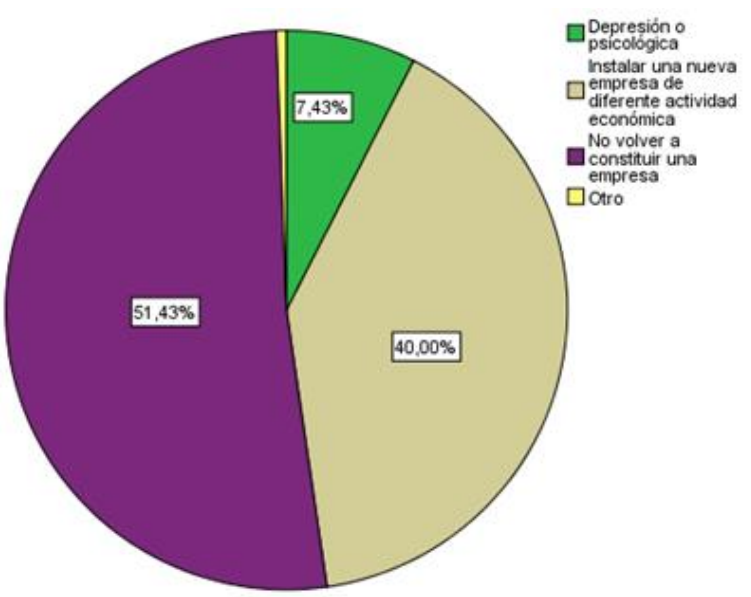

Esta grafica demuestra que el $51,43 \%$ de los empresarios tomo la decisión de no volver a constituir una empresas, afirman que los altos costos de arriendos y el aumento de los impuestos no les ayuda a querer seguir luchando por sus metas, el $40 \%$ prefirió instalar una nueva empresa pero de diferente actividad económica, el 7,43\% cayo en depresión ocasionando que no abriera otra empresa ha futuro.
Grafica 2. ¿Esta fue su primera empresa?

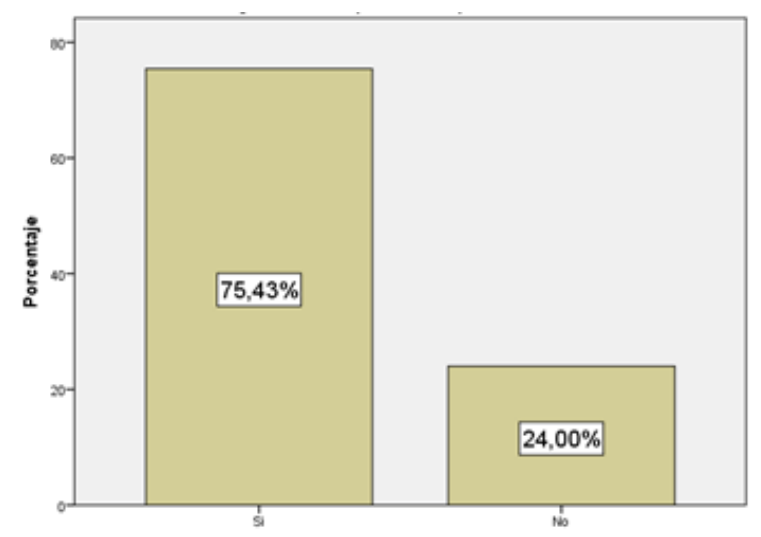

Dentro de la gráfica de tabla se puede concluir que dentro de los periodos comprendidos entre el 2009 hasta el 2013 fueron más las personas que crearon empresa por primera vez con un porcentaje del $75.43 \%$ y solo un $24 \%$ era su segunda o tercera vez creando empresa.

Grafica 3. ¿Cuántos años estuvo en funcionamiento la empresa?

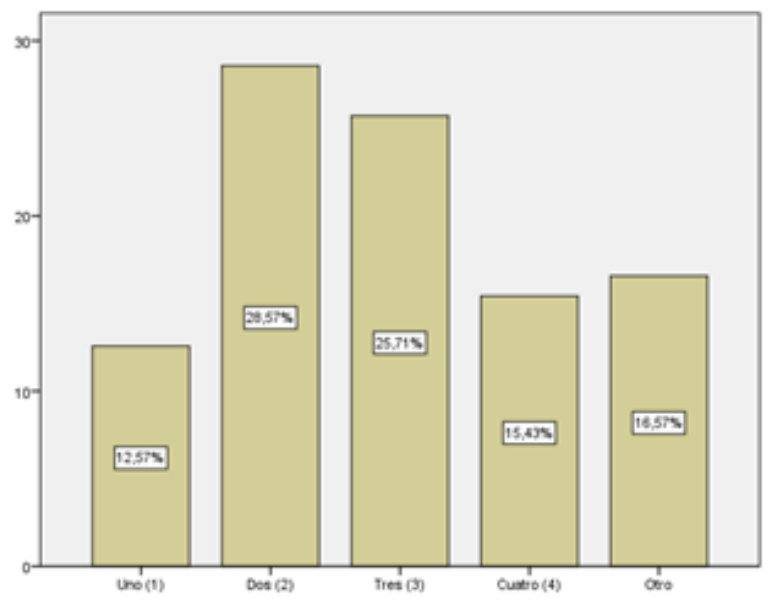

En la gráfica 3, se puede observar que el año de duración de una empresa en la ciudad de Barrancabermeja son dos con un $28,57 \%$, seguido de tres año equivalente al $25,71 \%$, después se encontró a otro que representa aquellos años superior a cinco con un $16,57 \%$ es decir muchas empresas si alcanzaron a estar en funcionamiento más de los cinco años.

Grafica 4. ¿Cuál es el grado más alto de formación del propietario y/o representante legal de la empresa? 


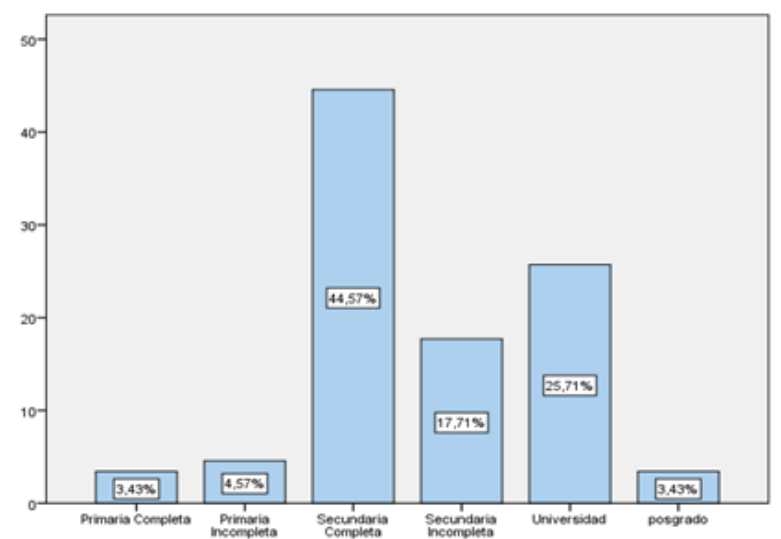

De la gráfica 4, podemos observar que el $44,57 \%$ de la población investigada tenían la secundaria completa, existe incluso un $25,71 \%$ que contada con certificación de título universitario, también que existe un $17,71 \%$ de los empresarios que no tiene la secundaria completa, el $4,57 \%$ posee la primaria incompleta otro $3,43 \%$ tiene la primaria completa, con el mismo porcentaje existe un pequeño número que cuenta con posgrado.

Grafica 5. ¿Cuáles fueron las principales fuentes de financiamiento al inicio de la empresa?* ¿Cuál era el sector económico al cual pertenecía la empresa?

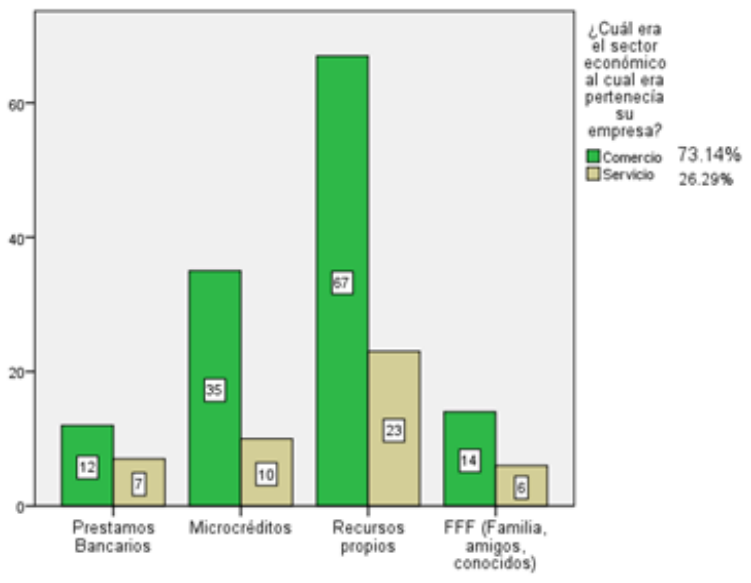

La grafica representa de color verde las empresas dedicadas al comercio que equivalen al $73,14 \%$ y de color beis la empresas dedicadas al servicio $26,29 \%$, se puede observar que 67 de los empresarios prefiere utilizar los recursos propios para constituir empresas en el área de comercio y 23 para el área de servicios siendo esta la principal fuente de financiamiento.

Tabla 2. ¿En cuál área de trabajo presento mayores dificultades al momento de dirigir su empresa?

\begin{tabular}{|ll|r|r|r|r|}
\hline & Frecuencia & Porcentaje & $\begin{array}{l}\text { Porcentaje } \\
\text { válido }\end{array}$ & $\begin{array}{l}\text { Porcentaje } \\
\text { acumulado }\end{array}$ \\
\hline Válido & & 1 &, 6 &, 6 &, 6 \\
& Contable & 17 & 9,7 & 9,7 & 10,3 \\
& administrativa & 72 & 41,1 & 41,1 & 51,4 \\
& Juridica & 11 & 6,3 & 6,3 & 57,7 \\
& Financiera & 61 & 34,9 & 34,9 & 92,6 \\
& Mercadeo & 13 & 7,4 & 7,4 & 100,0 \\
Total & 175 & 100,0 & 100,0 & \\
\hline
\end{tabular}

La tabla nos muestra que son el área administrativa con un $41.1 \%$ y financiera $34.9 \%$ la que presenta mayor dificultades para los empresarios por desconocer el manejo de inventarios, toman dinero de la empresa para gastos personales, no generan contratos laborales entre otra.

Grafica 6. De los siguientes elementos administrativos, con cuales contaba la empresa:

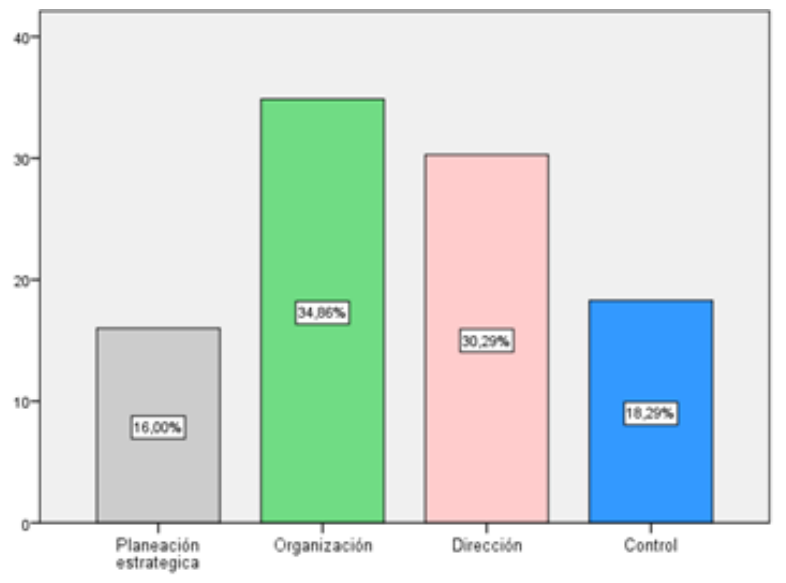

Varios de los empresarios que fueron encuestados afirmaban tener algún elemento administrativo, el 34,86\%, la segunda con mayor importancia es la dirección 30,29\% donde existía una comunicación, autoridad, supervisión y delegación para cada miembro después con 18,29\% está el control y la planeación estratégica, esta última con $16 \%$ es el proceso de determinar cómo una organización puede hacer el mejor uso posible de sus recursos (fuerza de trabajo, capital, clientes, etc.) en el futuro. 


\section{CONSECUENCIAS SOCIOECONÓMICAS A CAUSA DE LA LIQUIDACIÓN DE LAS EMPRESAS COMERCIALES Y DE SERVICIOS EN BARRANCABERMEJA}

\begin{tabular}{|c|c|c|}
\hline $\mathbf{R}$ & AFECTACION - CONSECUENCIA & PROPUESTA DE VALOR \\
\hline $\begin{array}{l}\text { Último nivel educativo alcanzado: } \\
\text { - Básica secundaria: } 28,0 \% \\
\text { - Básica primaria: } 16,4 \% \\
\text { - Universidad: } 8,8 \% \\
\text { - Posgrado: } 1,3 \% \\
\text { - Técnicos y Tecnólogos: } 6,3 \%\end{array}$ & \multirow{3}{*}{$\begin{array}{l}\text { Afecta el primer determinante de crecimiento } \\
\text { económico: "Recursos humanos (oferta de } \\
\text { trabajo, educación, disciplina, motivación)". } \\
\text { (Samuelson \& Nordhaus, 2004, p. 537). } \\
\text { Una sociedad que no cuente con un nivel } \\
\text { educativo óptimo no está en condiciones de } \\
\text { crear fuentes de sustento adecuados, primero } \\
\text { se debe ser competente y productivo, y } \\
\text { consecuentemente a ello, se logra un nivel y } \\
\text { calidad de vida dignos. } \\
\text { La educación logra un cambio de cultura y de } \\
\text { actitud en la gente, abre la mente a nuevas } \\
\text { posibilidades, ensancha el horizonte de vida, } \\
\text { permite el acceso a nuevas oportunidades y } \\
\text { hace que la persona esté en condiciones de } \\
\text { plantearse un proyecto de vida, lo cual } \\
\text { favorece la disminución de delitos, adicciones, } \\
\text { prostitución y corrupción. } \\
\text { A partir de los bajos índices de escolaridad que } \\
\text { existe en la población de Barrancabermeja, es } \\
\text { fácil entender que no se cuente con buenos } \\
\text { indicadores de desarrollo humano y de } \\
\text { ocupación adecuados. }\end{array}$} & \multirow{3}{*}{$\begin{array}{l}\text { El estado puede establecer políticas tendientes } \\
\text { a garantizar el acceso a la educación de alto } \\
\text { nivel. Con esta prioridad, un plan nacional por } \\
\text { la educación debe incluir la concientización a } \\
\text { nivel urbano y rural de toda la población, para } \\
\text { que entiendan la importancia de acceder a la } \\
\text { preparación y al conocimiento, lo cual es } \\
\text { fundamental para romper el lazo de la pobreza. } \\
\text { Interesante una sinergia Estado - Sociedad, } \\
\text { mediante una política de participación } \\
\text { ciudadana como instrumento de desarrollo } \\
\text { económico para la superación de la pobreza. }\end{array}$} \\
\hline $\begin{array}{l}\text {. Tasa de desempleo: } \\
19.9 \%=15.687 \text { personas } \\
\text {. Tasa de informalidad: } \\
21.6 \%=13.669 \text { personas } \\
\text {. Tasa de Subempleo: } \\
26 \%=16.436 \text { personas }\end{array}$ & & \\
\hline $\begin{array}{l}\text { Coeficiente de GINI: } 5.3 \% \\
\text {. Índice de Necesidades Básicas } \\
\text { Insatisfechas - NBI: } \\
15 \% \text {, de este porcentaje un } 12,4 \% \text { son } \\
\text { considerados pobres, y las personas en } \\
\text { situación de indigencia o miseria } \\
\text { alcanzan un } 2,5 \% \text {. } \\
\text {. Índice de Pobreza Multidimensional } \\
\text { (IPM): } 28.1 \%\end{array}$ & & \\
\hline $\begin{array}{c}\text { Recursos Naturales: } \\
\text { "Colombia Cuenta Con } 311 \text { Tipos De } \\
\text { Ecosistemas Continentales y } \\
\text { Costeros,.... } \\
\text {. Primer País: En Diversidad de Aves y } \\
\text { Orquídeas. } \\
\text { Segundo País: En Diversidad de } \\
\text { plantas, anfibios, peces dulce, acuícolas } \\
\text { y mariposas. } \\
\text {. Tercer país en diversidad de reptiles y } \\
\text { palmas. } \\
\text {. Cuarto país en diversidad de } \\
\text { mamíferos. } \\
\text { Colombia cuenta con } 32 \text { biomas } \\
\text { terrestres y } 314 \text { tipos de ecosistemas. El } \\
53 \% \text { del territorio son bosques naturales } \\
\text { continentales y el } 2 \% \text { páramos." (SIB, } \\
2002) \text {. }\end{array}$ & $\begin{array}{l}\text { Se dispone del segundo factor de crecimiento } \\
\text { económico: "Recursos naturales (tierra, } \\
\text { minerales, combustibles, calidad } \\
\text { ambiental)". (Samuelson \& Nordhaus, 2004, p. } \\
537 \text { ). } \\
\text { En este sentido todo está dado. } \\
\text { Barrancabermeja es una ciudad ubicada a } \\
\text { orillas del río Magdalena, arteria fluvial que } \\
\text { atraviesa el país de sur a norte y conecta al } \\
\text { país con el mar caribe; está ubicada en la parte } \\
\text { occidental del departamento de Santander, lo } \\
\text { que le brinda una excelente posición } \\
\text { geopolítica en el corazón de Colombia. } \\
\text { Es sede de la refinería de petróleo más grande } \\
\text { del país y es la capital de la Provincia de } \\
\text { Mares. Dista 101 km de la capital del } \\
\text { departamento Bucaramanga. } \\
\text { Es la ciudad más grande en la región del } \\
\text { Magdalena Medio y la segunda en todo su } \\
\text { departamento. } \\
\text { Posee un capital turístico por explorar, y está } \\
\text { proyectada a ser el mayor y más moderno } \\
\text { puerto multimodal de Colombia. Ciudad } \\
\text { cosmopolita que alberga una gran riqueza y } \\
\text { variedad cultural. }\end{array}$ & $\begin{array}{l}\text { Para el aprovechamiento de estos recursos, se } \\
\text { debe ir en el mismo sentido de la educación, } \\
\text { capacitación en la generación de proyectos } \\
\text { productivos, porque para crear un nuevo } \\
\text { negocio, como para acceder a fuentes de } \\
\text { empleo se debe estar preparado, ser } \\
\text { competente para desempeñar las vacantes que } \\
\text { demanda el mercado, y para acceder a los } \\
\text { recursos que brinda el gobierno dentro de sus } \\
\text { políticas de apoyo para la creación de } \\
\text { empresas en el país, las cuales deben ir } \\
\text { enfocadas al aprovechamiento de los recursos } \\
\text { existentes. En el caso de Barrancabermeja el } \\
\text { río Magdalena y sus ciénagas, la ubicación } \\
\text { geoestratégica, la petroquímica y el liderazgo } \\
\text { en la región. } \\
\text { Una buena oportunidad que se le presenta a la } \\
\text { fuerza laboral de Barrancabermeja, es lo } \\
\text { concerniente al transporte multimodal y la } \\
\text { logística del transporte. Los emprendedores } \\
\text { también pueden pensar en crear negocios de } \\
\text { suministro de bienes y servicios relacionados } \\
\text { con el tema portuario. } \\
\text { En Barrancabermeja y en general en Colombia, } \\
\text { es urgente salir de la producción de } \\
\text { commodities y pasar a la comercialización de } \\
\text { bienes y servicios con valor agregado, con }\end{array}$ \\
\hline
\end{tabular}


Olga Lucia Galvis Pinzón

\begin{tabular}{|c|c|c|}
\hline INDICADOR & AFECTACION - CONSECUENCIA & PROPUESTA DE VALOR \\
\hline & & $\begin{array}{l}\text { procesamiento que permitan sacar el mayor } \\
\text { margen de las materias primas que nos ofrece } \\
\text { el entorno, y acceder a los mercados, para que } \\
\text { las organizaciones sean competitivas. }\end{array}$ \\
\hline $\begin{array}{l}\text { Índice de creación de empresas: } \\
\text { Durante los años } 2009 \text { al } 2013 \text { se } \\
\text { constituyeron } 7.640 \text { empresas, y durante } \\
\text { el mismo período se cerraron } 2.867, \text { lo } \\
\text { cual equivale a una liquidación del } \\
37.52 \% \text { de las empresas creadas. } \\
\text { (Competitics, 2013). }\end{array}$ & $\begin{array}{l}\text { Afecta los siguientes focos de crecimiento: } \\
\text { "Tercer foco: Formación de Capital } \\
\text { (máquinas, fábricas, carreteras). } \\
\text { Y cuarto foco: Tecnología (ciencia, } \\
\text { ingeniería, administración, empresariado)." } \\
\text { (Samuelson \& Nordhaus, 2004, p. 537). } \\
\text { La no perdurabilidad de las empresas rompe } \\
\text { otro de los tópicos que caracterizan al } \\
\text { crecimiento económico, como es el equilibrio } \\
\text { que debe existir entre "El consumo, el ahorro y } \\
\text { la inversión" (Samuelson \&Nordhaus, 2004, } \\
\text { p.431). Estos tres tópicos juegan un papel } \\
\text { central en el desempeño económico de un } \\
\text { país, pues si se presenta un crecimiento rápido } \\
\text { del consumo y la inversión, aumenta el gasto } \\
\text { total, por lo cual se incrementa la productividad } \\
\text { y el empleo en el corto plazo. } \\
\text { En Barrancabermeja su dependencia del } \\
\text { negocio de la refinación de petróleo ha } \\
\text { propiciado un adormecimiento total en este } \\
\text { sentido, la innovación y la tecnología no están } \\
\text { dentro de las prioridades de la gente al } \\
\text { momento de crear empresa. Así mismo, es } \\
\text { común encontrar emprendedores que se } \\
\text { lanzan a la tarea de iniciar un negocio sin tener } \\
\text { la formación requerida para ello, llegando al } \\
\text { punto de no dar más y tienen que cerrar. } \\
\text { Dado lo anterior, es de esperarse un } \\
\text { precario crecimiento económico, y un } \\
\text { detrimento en la calidad y nivel de vida de la } \\
\text { población, es decir bajo desarrollo que es } \\
\text { equivalente a la prosperidad o bienestar } \\
\text { económico y social de sus habitantes. }\end{array}$ & $\begin{array}{l}\text { En Colombia se hace urgente que las } \\
\text { locomotoras de la infraestructura y la } \\
\text { innovación que propuso el gobierno del } \\
\text { presidente Juan Manuel Santos en su primer } \\
\text { gobierno, sean una realidad. } \\
\text { En el caso específico de Barrancabermeja, qué } \\
\text { bueno sería que la prioridad para la } \\
\text { administración municipal fuera la educación de } \\
\text { los barranqueños, puesto que a partir de ella el } \\
\text { crecimiento económico es posible, teniendo en } \\
\text { cuenta que las empresas las constituyen las } \\
\text { personas. } \\
\text { Las organizaciones deben sacar provecho de } \\
\text { los grupos de interés por el potencial de } \\
\text { comunicación que los mismos poseen, por } \\
\text { medio de ellos podrá identificar oportunidades y } \\
\text { desafíos para fructificarlos en su negocio. } \\
\text { La Cámara de Comercio puede coordinar } \\
\text { programas de capacitación para los } \\
\text { empresarios y hacer acompañamiento en la } \\
\text { búsqueda de las necesidades de los usuarios } \\
\text { para generar ideas de negocio y adquirir } \\
\text { competencias de dirección para que los } \\
\text { negocios estén bien sustentados, con un } \\
\text { enfoque en tecnología e innovación, lo cual } \\
\text { redundará en valor agregado para sus } \\
\text { productos y servicios, y en calidad de vida y } \\
\text { bienestar socioeconómico para la comunidad. }\end{array}$ \\
\hline
\end{tabular}

\section{ELEMENTOS DE JUICIO QUE PERMITAN AL EMPRESARIO ANTICIPARSE A LOS EVENTOS DE RIESGO INHERENTES A LA ACTIVIDAD EMPRESARIAL DE COMERCIO Y DE SERVICIOS.}

Para los autores Anthony \& Govindarajan (2006) "el control de gestión hace operacional la planeación estratégica. Mientras la planeación estratégica tiene qué ver con las grandes líneas de desarrollo de la organización en el mediano y largo plazo, para determinar directrices y políticas de gestión en horizontes de entre 3 y 5 años, el control de gestión se concentra en el corto plazo, sobre todo en los períodos anuales para definir los programas, los presupuestos y monitorizar el desempeño y el logro de los objetivos intermedios" citado por (Delicado 2014. Pág. 857). La Gestión Integral de Riesgo permite anticiparse al riesgo y asegurar los objetivos y metas estratégicas definidas por la empresa u organización, para ello en el proyecto se formularon acciones con la base de la existencia de las funciones básicas de las empresas y por la diversidad de actividades para alcanzar los objetivos y metas 
Tabla 3. Elementos de juicio para empresarios.

\begin{tabular}{|c|c|}
\hline AREAS & ACCIONES Y/O ELEEMENTOS \\
\hline DIRECCCION & $\begin{array}{l}\text { *Diseñar un perfil del trabajador que contenga las competencias y habilidades, la experiencia que } \\
\text { necesita y apoyarse de personal capacitado en psicología organizacional para enfocar al talento } \\
\text { humano. } \\
\text { *Descripción del puesto donde se detalla el contenido del cargo (requisito intrínseco de la empresa). } \\
\text { *Educación y Comunicación, para lograr la participación directa en los procesos de toma de decisiones } \\
\text { con la capacitación del personal. }\end{array}$ \\
\hline ADMINISTRACION & $\begin{array}{l}\text { *Formación administrativa, contable y financiera a empresarios. Cursos en las áreas a las que se } \\
\text { dedican la mayoría de las empresas de comercio y servicios en entidades públicas y privadas de la } \\
\text { región. } \\
\text { *Controlar el acceso a las instalaciones, ubicar equipos de seguridad dentro de la empresa, } \\
\text { contratación de seguros, tanto por incendios, como por riesgos ante terceros. } \\
\text { *Generar reportes mensuales de los problemas que se presentaron y las soluciones que dieron para } \\
\text { evitar la falta de comunicación y estar al tanto cada una de las partes sobre la situación de la empresa. } \\
{ }^{*} \text { Aplicar prácticas administrativas modernas, estableciendo una clara estrategia de sostenibilidad, con } \\
\text { políticas que den solidez a su organización, estableciendo de manera clara la misión y objetivos de su } \\
\text { negocio, con una visión proyectada al crecimiento de manera realista, para así efectuar una exitosa } \\
\text { gestión de los asuntos relevantes en temas sociales, ambientales y económicos. }\end{array}$ \\
\hline VENTAS & $\begin{array}{l}{ }^{*} \text { Construir un inventario a partir de los diferentes tipos existentes, crear políticas de los inventarios y } \\
\text { costos. } \\
{ }^{*} \text { Analizar el entorno empresarial, número de personas que pasan por la zona, los niveles de } \\
\text { accesibilidad y seguridad. } \\
{ }^{*} \text { Realizar un plan de Marketing o contratar personal para hacerlo. }\end{array}$ \\
\hline PRODUCCION & $\begin{array}{l}{ }^{*} \text { Comercializar bienes y servicios con valor agregado, con procesamiento que permitan sacar el mayor } \\
\text { margen de las materias primas que nos ofrece el entorno, y acceder a los mercados, para que las } \\
\text { organizaciones sean competitivas. } \\
\text { *Incursionar en temas de tecnología e innovación, como estrategias de sostenibilidad, lo cual le dará } \\
\text { mejores márgenes, además una creación de valor para la sociedad y el medio ambiente. }\end{array}$ \\
\hline CONTABILIDAD Y FINANZAS & $\begin{array}{l}\text { *Monitorear los gastos con la creación de un presupuesto para realizar una mejor practica del gasto que } \\
\text { llevará a convertirlo en utilidad. } \\
\text { *Construir una evaluación de la rentabilidad en las empresas, es decir analizar la liquidez, el margen de } \\
\text { solvencia, rentabilidad promedio, evaluación de cartera, entre otros indicadores con ayuda de un } \\
\text { administrador o economista. }\end{array}$ \\
\hline
\end{tabular}

\section{DISCUSIÓN}

Los empresarios deben identificar a profundidad cada una de las áreas de la empresa al igual que tener conocimiento de cada una de las herramientas que existen para ayudar a las empresas a superar crisis, avanzar o cambiar. Es fundamental reconocer que la Cámara de Comercio ofrece cursos gratuitos para cada empresario o persona que esté interesada en crear empresa a los cuales se pueden acceder en la página web. Igualmente $\mathrm{ACOPI}^{3}$ quienes están en capacidad de dar asesorías a aquellas empresas que presenten problemas y también brindan talleres para ayudar al empresario. Por su parte, está Expo-eventos, quienes realizan diplomados con costo pero que tiene beneficios para el empresario y su empresa, de esta manera se podría mitigar los cierres de empresas en Barrancabermeja. Las cifras que se han presentado, aunadas a los conceptos de los estudiosos que del tema se registran en este trabajo, dimensionan la problemática

\footnotetext{
${ }^{3}$ Asociación Colombiana de las micro, pequeñas y medianas empresas
}

socioeconómica, la cual se ha venido replicando a lo largo y ancho de la geografía nacional, dejando consecuencias negativas para la población. La falta de educación y de infraestructura son factores que no han permitido a Colombia avanzar en su desarrollo productivo, son los hitos en los que el gobierno debe enfocar sus políticas y esfuerzos, a partir de ello se genera innovación y desarrollo.

Durante las últimas décadas el gobierno ha creado leyes e instituciones que favorecen y apoyan la creación de empresas en el país, minimizando los trámites y apoyando financieramente a los emprendedores para que puedan hacer realidad sus ideas de negocios. El apoyo a la empresa debe ir de la mano con el mejoramiento continuo de las condiciones de accesibilidad y calidad de la educación. No obstante, la tarea debe ser en doble vía, es decir, la población debe prepararse para el desafío mediante la capacitación y el fortalecimiento de sus competencias, para hacer uso de los recursos. 
Por consiguiente el conocimiento en temas empresariales es fundamental para la toma de decisiones asertivas, se debe estudiar para adquirir las competencias de manejo y liderazgo, conocer el negocio que se proyecta y su entorno, estos son requisitos previos para fundar empresa.

El cierre de pequeños y grandes negocios, ya sea por falta de competitividad ante el ingreso de productos de otros países, o por escasa preparación del empresario, falta de conocimiento del entorno y del mercado, acarrea despido masivo de empleados en mayor o menor cantidad, empezando por el dueño del negocio.

Así mismo, la correcta intervención del estado es fundamental para el bienestar de la sociedad y el desarrollo de la economía, y las políticas de control de los derechos laborales y de los derechos de propiedad son igualmente saludables, para el estímulo y apoyo a la microempresa.

En efecto la conectividad hace que la producción de un país fluya, Colombia cuenta con salida por vía terrestre, aérea, fluvial y marítima, lo cual es una ventaja comparativa muy apetecida, sin embargo, no se tiene infraestructura de vías y transporte ni logística portuaria desarrolladas; siendo éstas ventajas competitivas fundamentales tanto a nivel interno, como ante el mundo globalizado.

Ahora bien el problema del desempleo se puede controlar, existen ejemplos de otros países a nivel mundial que lo han logrado basados en la educación y en el fortalecimiento del empresariado a nivel regional. Es prioritario detener la tendencia creciente de la informalidad de los empleos puesto que impacta negativamente el crecimiento económico, afecta la seguridad y acrecienta la problemática social, frenando el desarrollo económico y social. Existe la necesidad de la implantación de políticas que garanticen la formación del mayor capital que tiene el país, que es su gente. Pues las empresas y la riqueza, las generan las personas, las labores las realizan personas, y de ellas depende la calidad o el fracaso de toda producción de bienes o servicios.

La problemática que se ha estudiado resulta superable en la medida en que nos preparemos mejor para enfrentarla, para lo cual además se requiere de nuestro compromiso y esfuerzo.

\section{CONCLUSIONES:}

Los empresarios deben conocer a profundidad cada una de las áreas de la empresa al igual que tener conocimiento de los programas de que existen para ayudar a las empresas a superar crisis, avanzar o cambiar. Es importante comprender que siempre se presentaran diferentes factores que alteren el estado de la empresa, anteponerse a ellos es la cualidad que debe tener todo empresario. En efecto la duración de una empresa no recae únicamente en el grado de educación, se necesitan contar con buenas relaciones hacia los clientes y los proveedores, conocer las debilidades que tienen los empresarios para poder buscar a las personas o las formas para que éste no sea un punto de quiebre, sino una oportunidad de lograr y aprender competencias nuevas.

A pesar de todo existe la necesidad de la implantación de políticas que garanticen la formación del mayor capital que tiene el país, que es su gente. Pues las empresas y la riqueza, las generan las personas, las labores las realizan personas, y de ellas depende la calidad o el fracaso de toda producción de bienes o servicios.

\section{REFERENCIAS:}

Anthony \& Govindarajan (2006). Sistemas de gestión de control.

Beaver, W. (1966) Financial Ratios As Predictors of Failure. En : Journal of Accounting

CER. (2013). Centro de Estudios Regionales. Estudio Demográfico de Barrancabermeja.

COMPETITICS, (2013). Dinámica, Empresarial. Boletín $N^{\circ} 3$, Competitics Empresas constituidas en Barrancabermeja.

HERNANDEZ, R. (2006). Metodología de la investigación. Cuarta Edición. Mc. Graw Hill.

MUTIS, (2013). Valor compartido, una estrategia empresarial de alto impacto. http://www.elespectador.com/publicaciones/espec ial/valor-compartido-una-estrategia-empresarialde-alto-imp-articulo-428561.

OHLSON, J. (1980). Financial Ratios and the Probabilistic Prediction of Bankruptcy. En: Journal of Accounting Research, Vol. 18, No. 1, p. 109-131.

PORTE, M. \& KRAMER, M. (2011). La creación del valor compartido.

http://peru2021.org.pe/repositorioaps/0/0/par/crea cionvalorcompartido/shared $\% 20$ value $\% 20 \mathrm{in} \% 20$ s panish.pdf 
ROMERO, F. (2013). Alcances y limitaciones de los modelos de capacidad predictiva en el análisis del fracaso empresarial. http://publicaciones.eafit.edu.co/index.php/admini ster/article/view/2243/2143

SAMUELSON, P. A. \& NORDHAUS, W. D. (2005). Economía (pp. 431-537). México: McGraw-Hill Interamericana. Recuperado de https://unitecorporativa.files.wordpress.com/2013/ 02 leconomc3ada-18va-edicic3b3n-paul-asamuelson-william-d-nordhaus.pdf

SÁNCHEZ, C. (2005). La evaluación de la probabilidad de fracaso financiero.

SIB (2002). Sistema de información sobre Biodiversidad de Colombia. Recuperado de http://www.sibcolombia.net/web/sib/cifras

SORIANO, C. (2005) Porque fracasan las pymes http://www.gestiopolis.com/por-que-fracasan-laspymes/ 